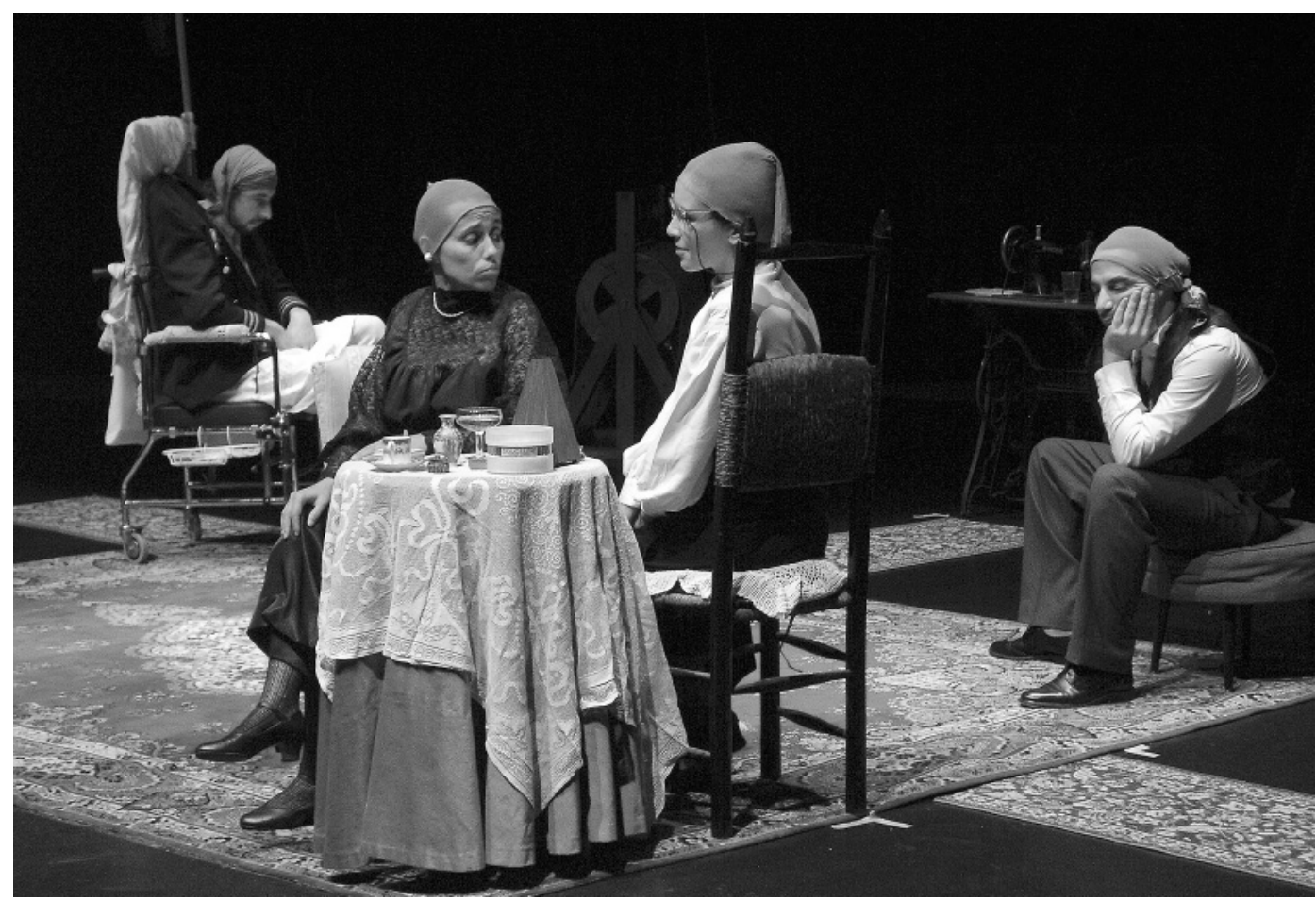

\title{
Estamos provavelmente no teatro
}

\section{Rui Pina Coelho}

Shadow Play / Jogo Sombra, de Maila Dimas, Susana Nunes, Carlos Marques e Francisco Campos. Encenação: Francisco Campos. Cenografia: Sara M. Graça. Figurinos: Andreia Rocha. Desenho de luz: Nuno Patinho. Co-Produção: Projecto Ruínas, 0 Espaço do Tempo, AL-MaSRAH Teatro e Câmara Municipal de Montemor-o-Novo. Local e data de estreia: Teatro Curvo Semedo, Montemor-oNovo, 25 de Setembro 2008.

Criado em 2001 e sediado em Montemor-o-Novo, 0 Projecto Ruinas assenta a sua actividade artística na transdisciplinaridade, recorrendo frequentemente ao cruzamento de diferentes estéticas e linguagens teatrais, do clown à técnica bufão, do grotesco ao absurdo, da Commedia dell'Arte ao realismo de "pia da cozinha" (kitchen sink). Sendo que a improvisação e a criação de textos originais marcará desde cedo as opções deste projecto, os primeiros trabalhos do colectivo denotavam uma especial atenção à intersecção entre as artes plásticas e o teatro, partindo de motivos pictóricos e explorando espaços não convencionais, numa lógica site-specific, em que se privilegiavam locais que estivessem, precisamente, em "ruinas". A propósito do primeiro espectáculo do colectivo, declarava-se:

Interessam-nos à partida locais construidos com funções especificas (igrejas, conventos, fábricas, castelos, armazéns, etc.) que, não sendo mais utilizados para a sua função inicial e mantendo uma forte carga histórica, emocional e estética, se insiram em comunidades que demonstrem interesse em dinamizar novos "velhos" espaços para intervenções culturais.

Este interesse e esta atitude não era meramente suportado por prerrogativas estéticas ou arquitectónicas, mas apresentava-se também como uma questão social e antropológica:

\begin{abstract}
A valorização extrema da funcionalidade, a importância dada à imagem física, tem vindo a alimentar comportamentos obsessivos em relação à perda de capacidades e à degradação do corpo. A convivência com espaços abandonados é de algum modo o terreno fértil para que estes medos e ansiedades ganhem intensidade. A analogia entre a ruina do espaço arquitectónico e a degradação do corpo humano materializarse-á numa abordagem plástica directamente decorrente da personalidade do espaço. Assim, a produção e integração dos elementos pictóricos deve funcionar de forma orgânica com o trabalho dos actores, no espaço.
\end{abstract}

Não obstante o demorado fôlego conceptual dos projectos, tratavam-se de espectáculos construídos declaradamente sob o signo do humor, do carnaval e da irrisão (Sátira em Ruinas, 2001; Gueto, 2002; As ilustres horas: De Haerecticis, 2003). Depois deste ciclo um outro núcleo temático começará a tomar forma: a atenção ao fenómeno da família e às pulsões existentes na unidade familiar ( 0 império contra-ataca, 2004; Comichão, 2005; Hans, o cavalo inteligente, 2006; 0 vizinho, 2007).

Em Voluntário 22 (2008) explorava-se o perigo de confiar de uma maneira acéfala nas autoridades, partindo de duas experiências de psicologia social: The Obedience Experiment de Stanley Milgram, e The Stanford Prison Experiment de Philip Zimbardo. A primeira destinava-se a perceber até que ponto os soldados nazis poderiam reclamar que apenas tinham cumprido ordens aquando da sua 


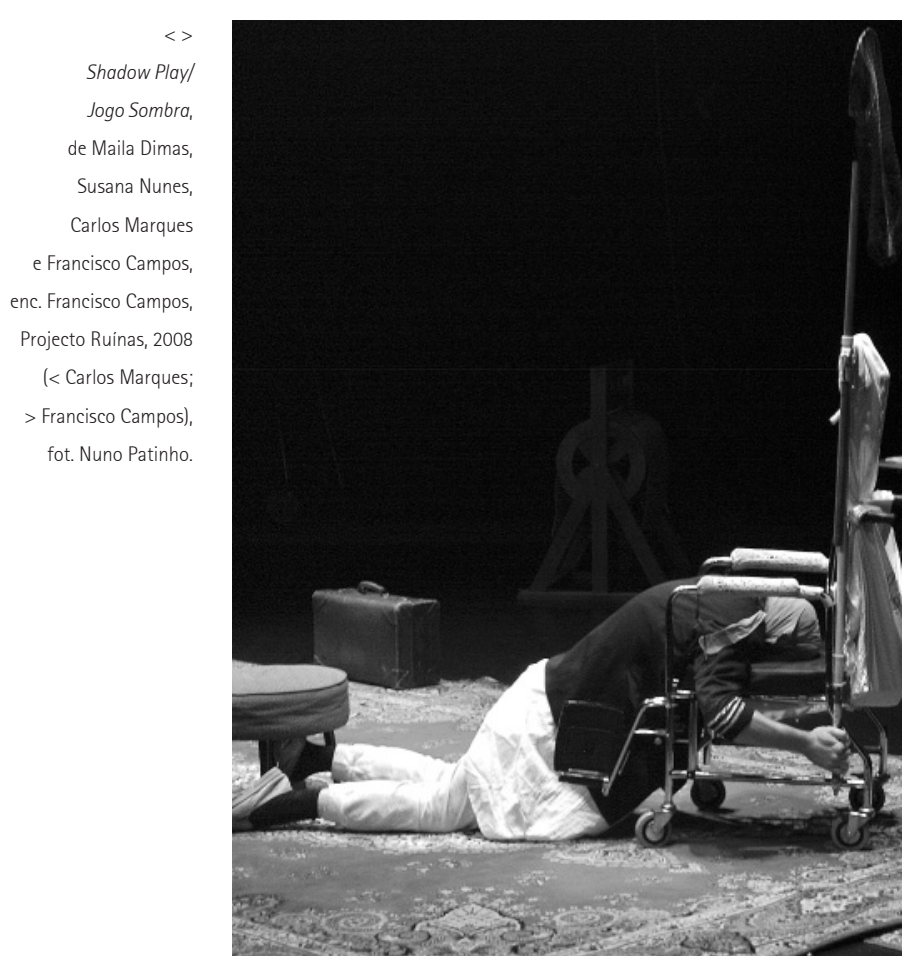

participação nas atrocidades perpetradas nos campos de concentração. Provou-se que na maioria dos casos os sujeitos não questionavam a autoridade, aplicando choques eléctricos, alegadamente letais, nas supostas vítimas. $\mathrm{Na}$ segunda obra descreve-se uma experiência em que os guardas prisionais executam ordens que punham em risco a vida e a dignidade dos reclusos, mesmo quando contrárias às suas próprias convicções morais.

Embora mascarado com elaboradas linguagens cénicas há nestes trabalhos um subtil namoro com o real e com o quotidiano, claramente visivel no espectáculo 0 vizinho (2007), onde se apresentavam linguagens inventadas, jogos fonéticos, rupturas e alternâncias entre registos interpretativos e uma partitura gestual de incrivel rigor, para tratar da solidão urbana, da falência dos valores que garantem a unidade e o equilíbrio social, do voyeurismo citadino e da crescente impossibilidade de comunicação entre um casal que se interessa progressivamente por um estranho vizinho. Tudo isto surgia servido numa estética kitchen sink, na medida em que se reconstituiam em palco os cenários domésticos com os respectivos objectos banais: as esfregonas, a roupa estendida, as latas e outros utensílios.

Em Shadow Play, a nona criação do grupo, regressase ao universo familiar. Tal como em outros trabalhos do Projecto Ruínas, o modelo de criação do espectáculo é o do devising. Kenneth Pickering define esta estratégia de invenção de um projecto performativo da seguinte maneira:

[U]ma forma de criar peças e espectáculos que não depende directamente de um texto pré-existente, mas que antes implica um grupo de actores na criação dos seus próprios textos. Os papéis tradicionais do encenado e do dramaturgo são substituidos pelo colectivo, ainda que, no final, um trabalho possa ser registado por escrito e encenado por um dos membros do grupo. (Pickering 2005:15, tradução minha).

Nas páginas do segundo número da revista Sinais de cena também Alexander Kelly se referia a esta estratégia nos seguintes modos:

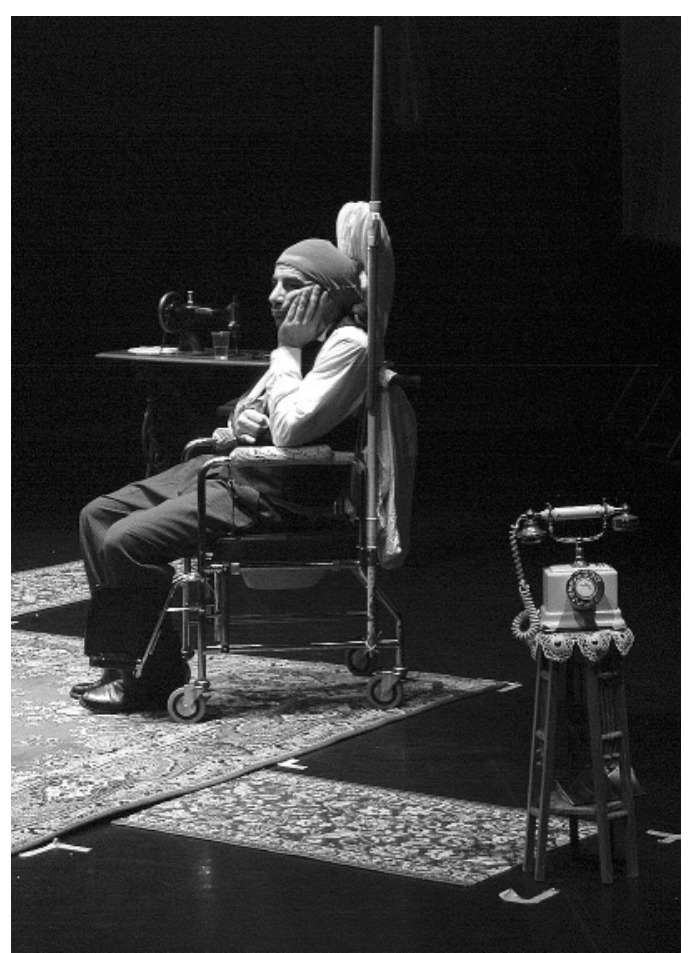

No teatro tradicional, o texto dramático é o ponto de partida, e o processo de ensaios consiste em passar para o palco uma interpretação desse texto. No devised theatre, qualquer outro elemento pode ser o ponto de partida: um tema, uma imagem do palco, uma ideia sobre como envolver o público, uma tarefa que se propõe aos performers. (Kelly 2004: 69).

Assim, Shadow Play foi escrito e concebido a partir de improvisações e de memórias pessoais dos intervenientes, tendo como alicerces uma "pesquisa sobre as pessoas às portas da morte, sobre a velhice, e sobre o silêncio" (sítio do colectivo). 0 resultado foi a criação de uma familia que destila memórias como se passeasse por um álbum de fotografias.

0 espectáculo é centrado em quatro personagens: D. Eduarda; o seu marido incapacitado, Becas (referência a Beckett?); e os seus dois filhos, Daniel e Maria. Tendo o texto sido criado a partir de "setenta e nove improvisações sobre uma familia de pessoas que aguardam o lanche por volta das cinco da tarde", Shadow Play instala-se numa cartografia edipiana, focando a disfuncionalidade do núcleo familiar. Numa narrativa aparentemente derivativa ou aleatória, abordam-se assuntos como a velhice, o fim do amor, a inveja, o suicídio, a homossexualidade encapuçada, a perversão sexual, a asfixia do núcleo familiar e a impossibilidade de o superar. 0 tom, dada a espessura da temática, é inusitadamente coloquial, sem grandes oscilações ou picos dramáticos, num compasso regular e em que a cada tentativa de alteração deste calmo batimento (com subidas do tom de voz ou com movimentações mais agressivas) a indiferença das restantes personagens rapidamente resgata o espectáculo, de novo, para uma passada mais tranquila, onde impera a conversa. Tudo avança calmamente e, assim, os segredos desta família vão sendo progressivamente revelados, ao sabor do diálogo. Vamos ficando a conhecer Eduarda, uma velha mãe que vai mantendo os seus filhos perto de si, ainda que sacrificando a felicidade da filha, Maria, solteira e 
dependente, e do filho, Daniel, enredado numa teia de jogos eróticos, tédio e desconforto. $E$, também Becas, 0 marido inválido, que já mal consegue articular as palavras e que é sordidamente mal-tratado pela familia, que ignora repetidamente e cruelmente os seus espasmos, quedas e convulsões. A esta claustrofobia familiar surgem, por contraponto, as referências a Mafalda, uma ex-namorada de Daniel que o terá abandonado e se terá mudado para Nova lorque, cidade que tem aqui a mesma função que Moscovo terá em Três irmãs, de Tchekov: sinónimo da última réstia de possivel felicidade.

Tudo isto surge polvilhado com um humor cáustico e negro, que em tudo remete para o teatro de Spiro Scimone, ou, pela mesma via, para a obra de Samuel Beckett, mas aqui cortejando o modelo da "peça de conversação" (conversation play) e a paisagem tchekoviana.

Mas um dos aspectos mais singulares deste espectáculo é, desde logo, a proposta que já se denuncia do próprio título: Shadow Play/Jogo sombra. Assim, a peça sobre esta familia estabelece um "jogo de sombras" com uma outra peça, que a emoldura, num dispositivo de teatro-dentrodo-teatro. Desta maneira, aquilo a que assistimos é a um grupo de actores que chega para apresentar uma peça, interpretando depois o insólito quarteto familiar. 0 quadro inicial, em que um actor se dirige directamente ao público, denúncia o jogo entre o real e a ficção que é uma das traves mestras deste espectáculo:

Boa noite, bem-vindos ao teatro. Maravilhoso público: atravessamos um periodo em que se intensifica o costume de repor peças. (...)

Deram-se conta provavelmente de que estamos no teatro, e que isto é um palco e que estas paredes são cenário. Sim, são falsas, é tudo cartão e madeira e tinta. Isto foi colocado aqui com um único

objectivo: o engano, a fraude. Os cortinados são falsos também, são de papier maché.

Esta descrição de objectos inexistentes (não há paredes de cenário, não há nada de cartão...) aponta para um jogo - ainda que um pouco ingénuo - entre a realidade e a ficção. Cenicamente, a separação entre o espectáculo e o espectáculo-dentro-do-espectáculo faz-se de uma maneira muito simples: os actores envergam uma meia de vidro na cabeça. De resto, trazem um figurino vagamente evocativo de um ambiente doméstico aristocrata do princípio do século XX (e lembramo-nos de novo de Tchekov...). São curiosos os momentos em que os actores propõem um cruzamento entre a verdade e a mentira, jogando com a meia de vidro, afastando-a da cabeça e criando a confusão sobre quem de facto é o emissor - se um dos quatro elementos da familia, se um dos actorespersonagem.
De resto, todo o espectáculo decorre num aparato cénico brookiano: sobre tapetes e com parcos recursos cenográficos. Assim, um grande tapete quadrado é intersectado nas pontas por quatro pequenas línguas (que Ihe dão um aspecto de estrela). Em cada uma das extremidades destas passadeiras encontra-se um objecto: um telefone, uma máquina de costura, um metrónomo e um rádio. Ao centro encontrar-se-ão mesas e cadeiras, que circularão pelo tapete, em diferentes composições, ao longo do espectáculo. De recorte assinalável é também a cadeira de Becas, numa vaga alusão à cadeira de Hamm, em Endgame. Embora a cenografia de Sara M. Graça seja de uma atenção e cuidado irrepreensiveis, há elementos que não ultrapassam a mera função decorativa e que a encenação de Francisco Campos poderia ter integrado de maneira mais eficaz: refiro-me em particular aos elementos que se encontram nas extremidades dos pequenos tapetes e que, por isso mesmo, têm uma posição de particular destaque.

0 quarteto de actores joga em diversos registos, do clownesco à comédia de palavra, não mostrando fragilidades em nenhum deles e assegurando interpretações equilibradas e que mantiveram sempre um interessante grau de suspensão e imprevisibilidade - fundamentais a um projecto com estas características.

Não obstante toda a inegável qualidade e o interesse do espectáculo, há contudo alguma timidez na exploração dos temas, substituindo-se, por vezes a lógica ácida à pragmática cénica, encontrando-se soluções, sem dúvida, eficazes, mas que retiram alguma da tensão e inquietude que o texto vai aportando, atirando-o para uma zona mais ligeira. Assim, ainda que com algumas fragilidades, Shadow Play marca um feliz momento no trajecto do Projecto Ruínas que, notoriamente, vai merecendo mais visibilidade e atenção.

\section{Referências bibliográficas}

KELLY, Alexander (2004), "Ensinando encenando devising", Sinais de cena, n'.2, Dezembro, pp. 69-71.

PICKERING, Kenneth (2005), Key Concepts in Drama and Performance. Houndmills, Basingstoke \& Hampshire: Palgrave Macmillan.

\section{Outras referências}

http://www.projectoruinas.blogspot.com/ 